\title{
Growth and alignment of the pediatric subaxial cervical spine following rigid instrumentation and fusion: a multicenter study of the Pediatric Craniocervical Society
}

\author{
Hannah E. Goldstein, MD, ${ }^{1}$ Justin A. Neira, MD, ${ }^{1}$ Matei Banu, MD, ${ }^{1}$ Philipp R. Aldana, MD, ${ }^{2}$ \\ Bruno P. Braga, MD, ${ }^{3}$ Douglas L. Brockmeyer, MD, ${ }^{4}$ Michael L. DiLuna, MD, ${ }^{5}$ \\ Daniel H. Fulkerson, MD, ${ }^{6}$ Todd C. Hankinson, MD, ${ }^{7}$ Andrew H. Jea, MD, MHA, ${ }^{6}$ Sean M. Lew, MD, ${ }^{8}$ \\ David D. Limbrick, MD, PhD, ${ }^{9}$ Jonathan Martin, MD, ${ }^{10}$ Joshua M. Pahys, MD,11 \\ Luis F. Rodriguez, MD, ${ }^{12}$ Curtis J. Rozzelle, MD, ${ }^{13}$ Gerald F. Tuite, MD, ${ }^{12}$ Nicholas M. Wetjen, MD, ${ }^{14}$ \\ and Richard C. E. Anderson, MD ${ }^{1}$
}

\begin{abstract}
1Department of Pediatric Neurosurgery, Children's Hospital of New York, Columbia-Presbyterian, New York, New York; 'Division of Pediatric Neurosurgery, University of Florida College of Medicine, Jacksonville, Florida; ${ }^{3}$ Department of Neurological Surgery, UT Southwestern Medical Center, Dallas, Texas; ${ }^{2}$ Department of Pediatric Neurosurgery, Primary Children's Hospital, University of Utah, Salt Lake City, Utah; ' ${ }^{D}$ epartment of Pediatric Neurosurgery, Yale School of Medicine, New Haven, Connecticut; ${ }^{6}$ Department of Neurological Surgery, Goodman Campbell Brain and Spine, Indiana University School of Medicine, Indianapolis, Indiana; ${ }^{7}$ Department of Neurosurgery, University of Colorado School of Medicine, Aurora, Colorado; ${ }^{8}$ Department of Neurosurgery, Children's Hospital of Wisconsin, Milwaukee, Wisconsin; 'Department of Neurological Surgery, St. Louis Children's Hospital, Washington University School of Medicine, St. Louis, Missouri; ${ }^{10}$ Department of Neurosurgery, Connecticut Children's Medical Center, Hartford, Connecticut; ${ }^{11}$ Department of Orthopedic Surgery, Shriners Hospitals for Children, Philadelphia, Pennsylvania; ${ }^{12}$ Department of Neurosurgery, Johns Hopkins All Children's Hospital, St. Petersburg, Florida; ${ }^{13}$ Division of Neurosurgery, Children's of Alabama, Birmingham, Alabama; and ${ }^{14}$ Department of Neurosurgery, Mayo Clinic, Rochester, Minnesota
\end{abstract}

\begin{abstract}
OBJECTIVE The long-term effects of surgical fusion on the growing subaxial cervical spine are largely unknown. Recent cross-sectional studies have demonstrated that there is continued growth of the cervical spine through the teenage years. The purpose of this multicenter study was to determine the effects of rigid instrumentation and fusion on the growing subaxial cervical spine by investigating vertical growth, cervical alignment, cervical curvature, and adjacent-segment instability over time.
\end{abstract}

METHODS A total of 15 centers participated in this multi-institutional retrospective study. Cases involving children less than 16 years of age who underwent rigid instrumentation and fusion of the subaxial cervical spine (C-2 and T-1 inclusive) with at least 1 year of clinical and radiographic follow-up were investigated. Charts were reviewed for clinical data. Postoperative and most recent radiographs, CT, and MR images were used to measure vertical growth and assess alignment and stability.

RESULTS Eighty-one patients were included in the study, with a mean follow-up of 33 months. Ninety-five percent of patients had complete clinical resolution or significant improvement in symptoms. Postoperative cervical kyphosis was seen in only 4 patients (5\%), and none developed a swan-neck deformity, unintended adjacent-level fusion, or instability. Of patients with at least 2 years of follow-up, $62 \%$ demonstrated growth across the fusion construct. On average, vertical growth was 79\% (4-level constructs), $83 \%$ (3-level constructs), or 100\% (2-level constructs) of expected growth. When comparing the group with continued vertical growth to the one without growth, there were no statistically significant differences in terms of age, sex, underlying etiology, surgical approach, or number of levels fused.

CONCLUSIONS Continued vertical growth of the subaxial spine occurs in nearly two-thirds of children after rigid instrumentation and fusion of the subaxial spine. Failure of continued vertical growth is not associated with the patient's age, sex, underlying etiology, number of levels fused, or surgical approach. Further studies are needed to understand this dichotomy and determine the long-term biomechanical effects of surgery on the growing pediatric cervical spine.

https://thejns.org/doi/abs/10.3171/2018.1.PEDS17551

KEYWORDS subaxial spine; cervical; fusion; growth; alignment; stability 
I $\mathrm{T}$ is well known that the pediatric cervical spine is not just a smaller version of the adult cervical spine. Important structural and biomechanical differences exist that allow for normal growth and development, but which also lead to unique patterns of injury and instability requiring surgical intervention. ${ }^{3-5,7,9,13,16,18,24}$ Although many advances have been made in rigid instrumentation and fusion of the pediatric cervical spine over the past 20 years, ${ }^{6,7,10,11,18}$ the effects of instrumentation and fusion on the future growth and alignment of the pediatric cervical spine are not well understood.

Conventional understanding has been that the pediatric cervical spine reaches biomechanical maturity around 9-10 years of age.22 Recent evidence, however, suggests that vertical growth continues up to age 18 in boys and age 14 in girls, ${ }^{14}$ making understanding of the effects of instrumentation and fusion through the teenage years clinically important. Furthermore, approximately $75 \%$ of the total growth of the pediatric cervical spine occurs throughout the subaxial spine. Prior studies have shown that rigid fusion of the thoracic spine prior to growth maturity has deleterious effects on both cardiopulmonary function and overall skeletal growth. ${ }^{23,26,30}$ Yet there is increasing evidence that instrumentation at the craniovertebral junction in the pediatric population is well tolerated, as there is continued growth across the fusion construct and overall maintained alignment in the vast majority of patients. . $2,15,17,20,21,29$

Pediatric neurosurgeons are often asked to evaluate children with varying degrees of subaxial spine pathology for cervical spine instrumentation and fusion. Parents may ask about prognosis and long-term effects of both the underlying pathology and the proposed surgical intervention. The purpose of this multicenter study was to determine the effects of rigid instrumentation and fusion on the growing subaxial cervical spine by investigating vertical growth, cervical alignment, cervical curvature, and adjacent-segment instability over time.

\section{Methods}

After institutional review board approval was obtained from each institution, de-identified data were collected from pediatric neurosurgeons at 15 children's hospitals across the country. Inclusion criteria were 1) children who underwent rigid instrumentation and fusion of the subaxial cervical spine (C-2 and T-1 inclusive), 2) age less than 16 years at the time of surgery, 3 ) radiographically documented postoperative fusion (CT or radiographs), 4) a minimum of 1 year of both clinical and radiographic follow-up data, and 5) available imaging studies (CT, upright radiographs, or MRI) with measurement bars preoperatively, postoperatively (within 1 month of surgery), and at long-term followup. If imaging was available from multiple follow-up visits, the most recent follow-up radiograph was used. Patients were excluded if the quality of the imaging studies precluded accurate measurements.

Clinical data collected included age, sex, etiology, presenting symptoms, and symptoms during follow-up. Surgical data collected included levels fused and surgical approach (anterior, posterior, or both). Imaging stud-
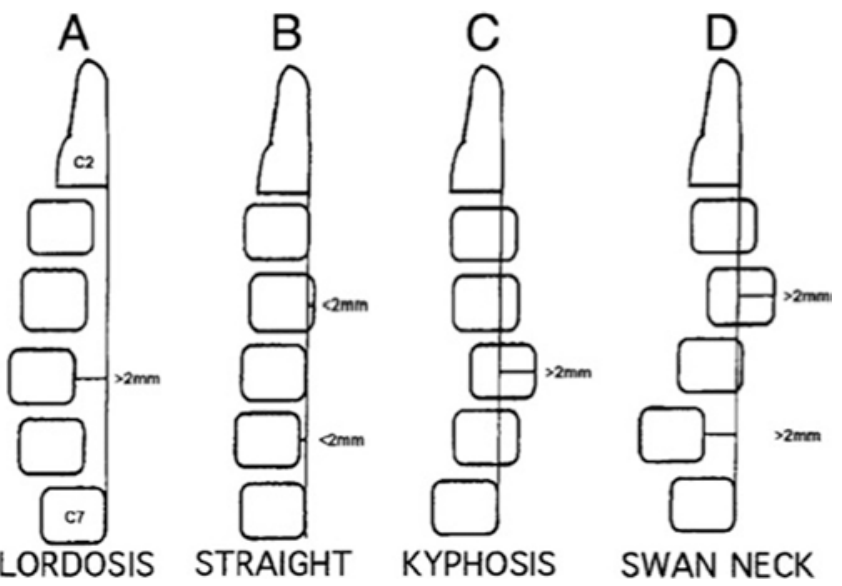

FIG. 1. Alignment classification. Drawing depicting the classification of cervical spine alignment into 4 groups based on the direction and extent of displacement of the vertebral bodies from a line drawn between the posterior border of C-2 and C-7. Lordosis (A) has anterior displacement greater than $2 \mathrm{~mm}$, straight alignment (B) has anterior or posterior displacement within $2 \mathrm{~mm}$, kyphosis (C) has posterior displacement greater than $2 \mathrm{~mm}$, and swan-neck deformity (D) has simultaneous anterior and posterior displacement greater than $2 \mathrm{~mm}$. Modified from Toyama et al.: Realignment of postoperative cervical kyphosis in children by vertebral remodeling. Spine (Phila Pa 1976) 19(22):2565-2570, 1994, https:// journals.Iww.com/spinejournal/toc/1994/11001.

ies were assessed for unintentional adjacent-segment fusion or instability. As in prior studies, cervical alignment was measured and categorized according to the technique described by Toyama et al. ${ }^{25}$ (Fig. 1). Measurements were performed to assess vertical (rostral-caudal) growth across the fused construct as well as across the entire subaxial spine. The height of the entire subaxial spine was measured from the midsagittal inferior endplate of C-2 to the midsagittal inferior endplate of $\mathrm{C}-7$, consistent with the measurements performed in our previous work describing normal cervical spine growth. ${ }^{14}$ The height of the fusion construct was measured from the midsagittal superior endplate of the most rostral level of the fusion construct to the midsagittal inferior endplate of the caudal-most level of the construct (Fig. 2). Based on work by Johnson et al. looking
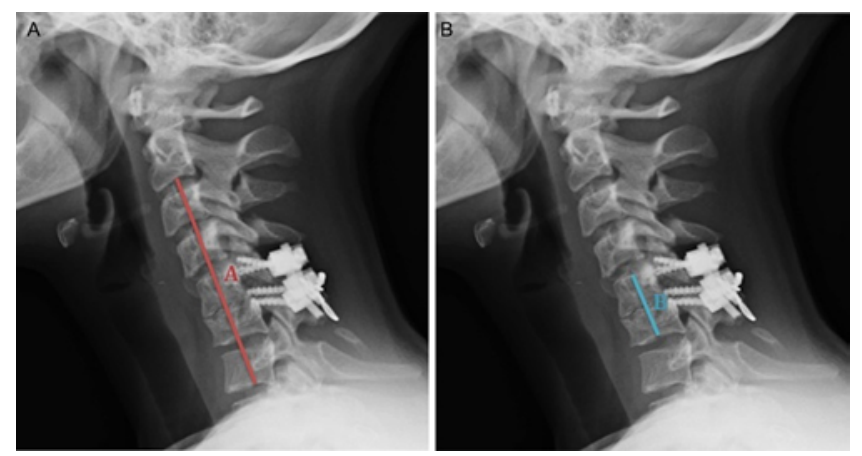

FIG. 2. A: Measurement of the entire subaxial spine from the midsagittal inferior endplate of $\mathrm{C}-2$ to the midsagittal inferior endplate of C-7. $\mathrm{B}$ : Measurement of the fused construct from the midsagittal superior endplate of the most rostral level of the fusion construct to the midsagittal inferior endplate of the caudal-most level of the construct. Figure is available in color online only. 
at the normal growth of the subaxial spine, on average only $2.63 \mathrm{~mm}$ (females) to $3.00 \mathrm{~mm}$ (males) of growth across the entire subaxial spine per year is expected. ${ }^{14}$ This works out to less than $1.5 \mathrm{~mm}$ of expected growth across the average 3-level fusion construct over a single year, a quantity that may be too small to measure reliably. Therefore, we limited further growth analysis only to patients who had at least 2 years of follow-up.

Adjacent-level instability was defined using standard radiographic criteria from White and Panjabi et al. ${ }^{27,28}$ All measurements were made by 2 independent neurosurgeons, and any discrepancy of more than $0.5 \mathrm{~mm}$ was double-checked for accuracy and confirmed by a third neurosurgeon. Measurements of the spinal canal diameter were not performed because there is no substantial change after 4 years of age in either boys or girls. ${ }^{14}$ All measurements were made on both immediate postoperative images as well as the most recent available follow-up studies.

\section{Statistical Analysis}

All statistical tests were conducted using IBM SPSS software (version 23.0 for Macintosh, IBM Corp.). Pearson's chi-square test was used to compare patients with and without growth based on pathology, presenting symptoms, or surgical approach. Fisher's exact test was used to determine the role of sex as a predictor of growth. Continuous variables were compared between patients with and without postoperative growth by univariate ANOVA or independent-samples t-test. A p value $<0.05$ was considered statistically significant.

\section{Results}

Eighty-one patients from 15 institutions were included in the study, with a mean follow-up of 33 months (range 12-113 months). The mean age at the time of initial surgery was 11.6 years old, with a range of 2-15 years. Fortyfour of the 81 patients $(54 \%)$ were boys. The most common presenting etiology was trauma, accounting for 44 of the 81 cases included (54\%). Other common etiologies included neoplastic causes and congenital anomalies, each accounting for $20 \%$ of patients studied. Most patients (50 [62\%] of 81) presented with neck pain; 20 patients $(25 \%)$ had some degree of myelopathy, and 12 patients $(15 \%)$ had radicular pain. Forty-six patients $(57 \%)$ underwent a posterior fusion, 26 patients (32\%) underwent an anterior fusion, and 9 patients (11\%) had a combined anterior/posterior approach. The mean number of levels fused was 3 , with a range of 2 to all 7 levels of the subaxial cervical spine (C-2 and T-1 inclusive) included in the fusion construct.

\section{Clinical Symptoms, Cervical Alignment, and Adjacent-Level Instability}

Ninety-five percent of patients (77 of 81) had complete clinical resolution or significant improvement in symptoms. Four percent reported no change in symptoms, and only 1 patient had clinical worsening, which, upon further review, was attributable to tumor progression rather than to the surgery or the fusion construct itself. Most patients -77 (95\%) of 81-maintained a lordotic or straight subaxial spine alignment following surgery. Postoperative
TABLE 1. Summary of demographic and clinical characteristics of the 81 patients included in this study

\begin{tabular}{|c|c|}
\hline Characteristic & Value \\
\hline \multicolumn{2}{|l|}{ Sex } \\
\hline Boys & $44(54)$ \\
\hline Girls & $37(46)$ \\
\hline \multicolumn{2}{|l|}{ Age in yrs } \\
\hline Mean & 11.6 \\
\hline Range & $2-15$ \\
\hline \multicolumn{2}{|l|}{ Etiology } \\
\hline Traumatic & $44(54)$ \\
\hline Congenital & $16(20)$ \\
\hline Neoplastic & $16(20)$ \\
\hline Other & $5(6)$ \\
\hline \multicolumn{2}{|l|}{ Presentation } \\
\hline Neck pain & $50(62)$ \\
\hline Radicular pain & $12(15)$ \\
\hline Myelopathy & $20(25)$ \\
\hline Other & $6(7)$ \\
\hline \multicolumn{2}{|l|}{ Length of follow-up in mos } \\
\hline Mean & 32.7 \\
\hline Range & $12-113$ \\
\hline \multicolumn{2}{|l|}{ Surgical technique } \\
\hline Anterior approach & $26(32)$ \\
\hline Posterior approach & $46(57)$ \\
\hline Both & $9(11)$ \\
\hline \multicolumn{2}{|l|}{ No. of levels fused } \\
\hline Mean & 3 \\
\hline Range & $2-7$ \\
\hline \multicolumn{2}{|l|}{ Clinical outcome } \\
\hline Resolution of Sx & $49(60)$ \\
\hline Improvement of Sx & $28(35)$ \\
\hline No change in Sx & $3(4)$ \\
\hline Worsening of Sx & $1(1)$ \\
\hline \multicolumn{2}{|l|}{ Post alignment } \\
\hline Lordotic or straight & $77(95)$ \\
\hline Kyphotic & $4(5)$ \\
\hline Swan neck & 0 \\
\hline Adjacent-segment instability & 0 \\
\hline Adjacent-segment fusion & 0 \\
\hline
\end{tabular}

cervical kyphosis was seen in 4 patients (5\%), and none developed a swan-neck deformity. At a mean follow-up of 33 months, there were no cases of unintended adjacentlevel fusion or instability (Table 1).

\section{Vertical Growth}

Taking the cohort as a whole, $40(49 \%)$ of the 81 patients demonstrated vertical growth across the fusion construct during the follow-up period. Forty-five patients had at least 2 years of follow-up data (mean follow-up 47 months, range $24-113$ months). There were no statistically 

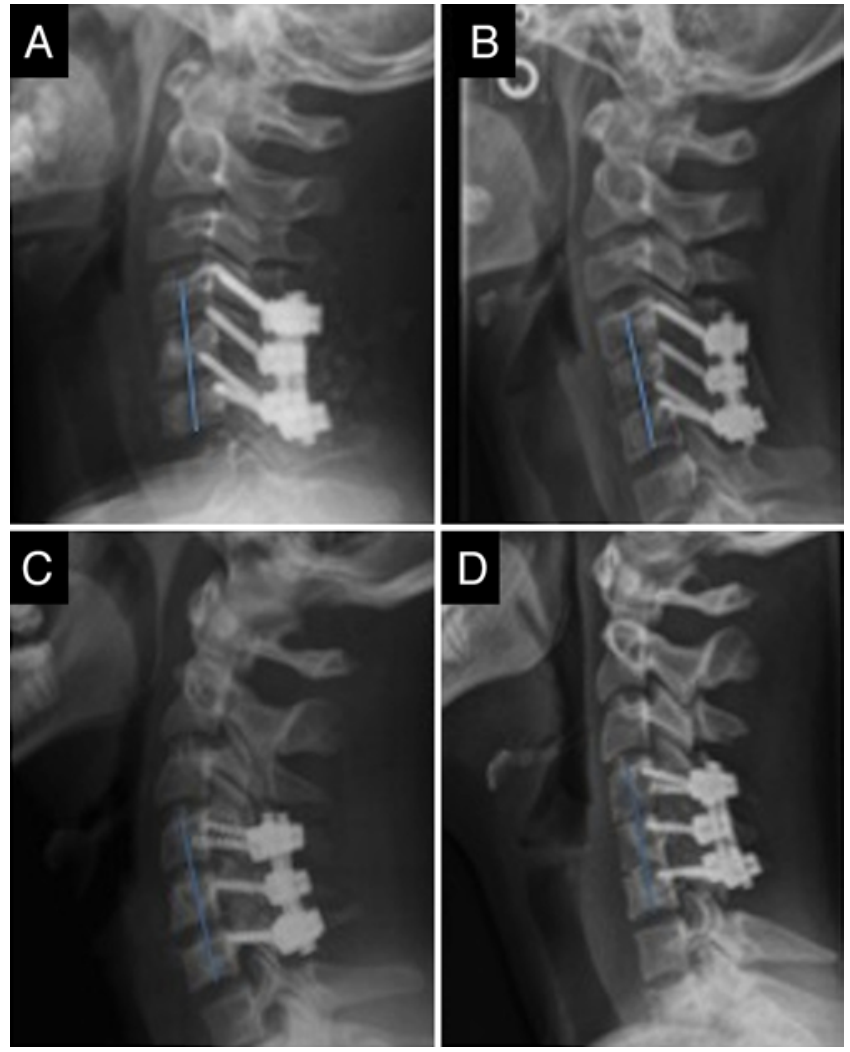

FIG. 3. A and B: Immediate postoperative (A) and 45-month follow-up (B) upright lateral radiographs obtained in a female patient who underwent C4-6 posterior instrumentation and fusion at the age of 9 years. The radiograph obtained 45 months after surgery shows $40 \%$ growth across the fusion construct. C and D: Immediate postoperative (C) and 83-month follow-up (D) upright lateral radiographs obtained in a female patient who underwent $C 4-6$ posterior instrumentation and fusion at the age of 13 years. The radiograph obtained 83 months after surgery demonstrates no growth across the fusion construct (measurement indicated by blue lines). Figure is available in color online only. significant differences in this group compared to the entire cohort regarding age, sex, etiology, symptoms, surgical approach, or number of levels fused.

Overall, 28 (62\%) of the 45 patients with at least 2 years of follow-up demonstrated growth across the fusion construct, while 17 (38\%) of the 45 patients did not (Fig. 3). Comparing the group with continued vertical growth to the one without growth showed no statistically significant differences in terms of age, sex, underlying etiology, surgical approach, or number of levels fused. Further analysis was done by subgroup, based on the number of levels fused. Three patients with at least 2 years of follow-up were excluded from this analysis as there was only 1 patient each who underwent a 5-level, a 6-level, and a 7-level fusion, making subgroup analyses of these patients underpowered.

\section{Two-Level Constructs}

A total of 13 patients with at least 2 years of followup underwent 2-level fusions. The mean follow-up in this group was 48 months. Of the 13 patients, 8 (62\%) had continued vertical growth across the fusion construct, while $5(38 \%)$ had no measureable growth over the follow-up period. In the patients in whom vertical growth occurred, the growth across the fusion construct accounted for an average of $41 \%$ (range $33 \%-47 \%$ ) of the growth of the entire subaxial spine. This compares to $40 \%$ growth of the subaxial spine that would be expected across 2 levels in a normal spine over the same duration of follow-up, resulting in a growth rate across the fusion construct that was greater than $100 \%$ of normal (Fig. 4).

\section{Three-Level Constructs}

Twenty-two patients with at least 2 years of follow-up underwent 3-level fusions. The mean follow-up in this group was 42 months. Of the 22 patients, 14 (64\%) demonstrated continued vertical growth across the fusion con-

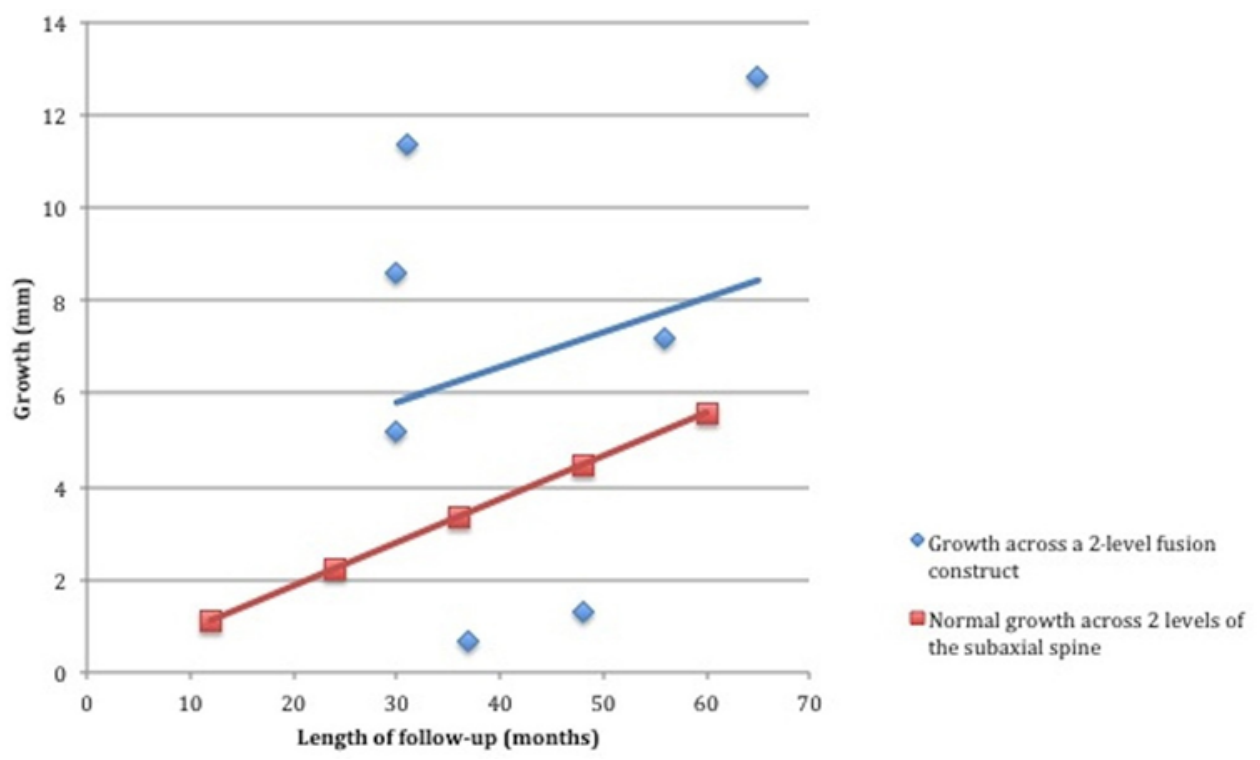

FIG. 4. Growth across the fusion construct in patients with continued growth and at least 2 years of follow-up after a 2-level fusion compared to expected growth across 2 levels of the normal pediatric subaxial spine. The slopes of the lines represent the rate of growth. Figure is available in color online only. 


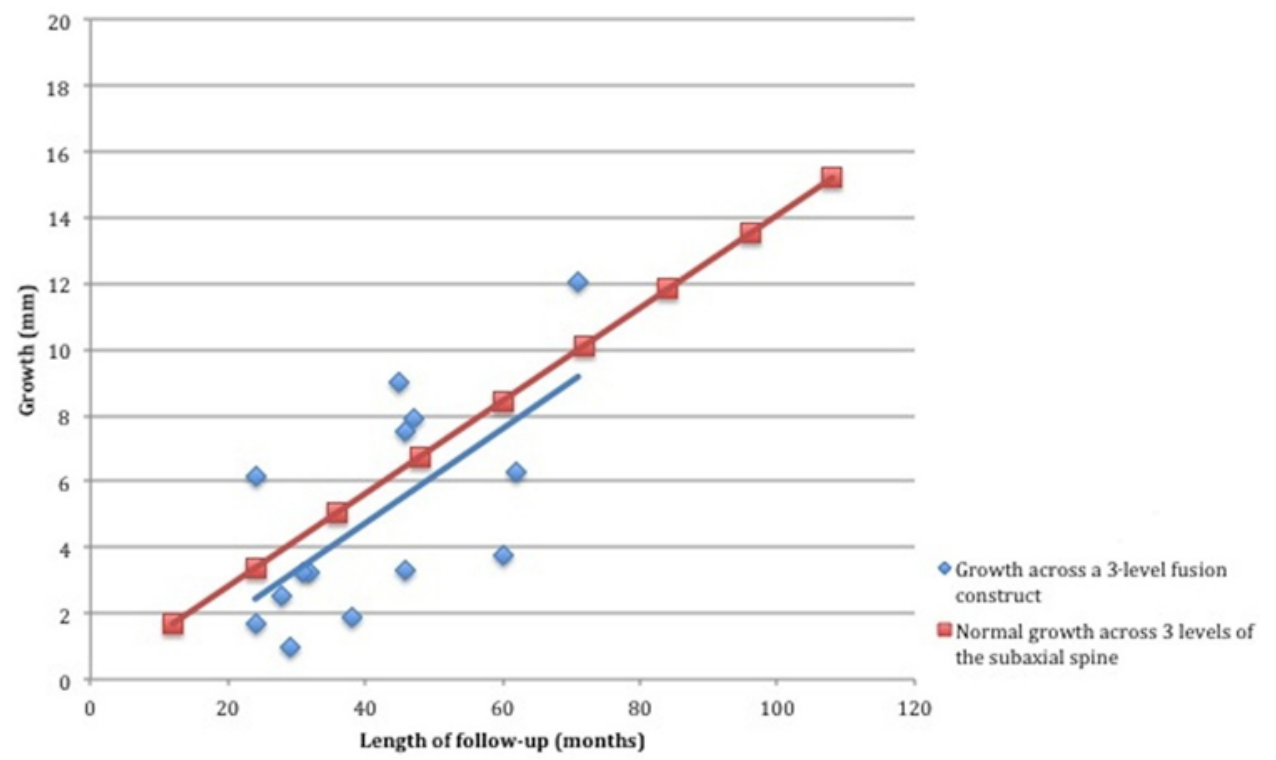

FIG. 5. Growth across the fusion construct in patients with continued growth and at least 2 years of follow-up after a 3-level fusion compared to expected growth across 3 levels of the normal pediatric subaxial spine. The slopes of the lines represent the rate of growth. Figure is available in color online only.

struct, while 8 patients (36\%) did not. Growth across the fusion construct accounted for an average of $50 \%$ (range $21 \%-72 \%$ ) of the growth of the entire subaxial spine. This compares to the $60 \%$ of growth of the subaxial spine that would be expected across 3 levels in a nonfused spine over the same follow-up period, or $83 \%(50 / 60)$ of the normal growth rate (Fig. 5).

\section{Four-Level Constructs}

Seven patients with at least 2 years of follow-up underwent 4-level fusions. The mean follow-up in this group was 53 months. Of these 7 patients, 5 (71\%) had continued growth across the fusion construct, while $2(29 \%)$ had no measurable growth over the follow-up period. In the 5 patients with continued growth, growth across the fusion construct accounted for an average of 63\% (range 50\%$80 \%$ ) of the growth of the entire subaxial spine. This compares to $80 \%$ of growth of the subaxial spine that would be expected across 4 levels in a normal spine over the same follow-up period, or a growth rate that is 79\% (63/80) of normal (Fig. 6).

\section{Five-, Six-, and Seven-Level Constructs}

There was 1 patient each with a 5-, 6-, and 7-level construct and at least 2 years of follow-up. The 5-level and 6-level construct patients each showed no growth across the fusion construct during the follow-up period. However, the patient with the 7-level construct, followed for 103

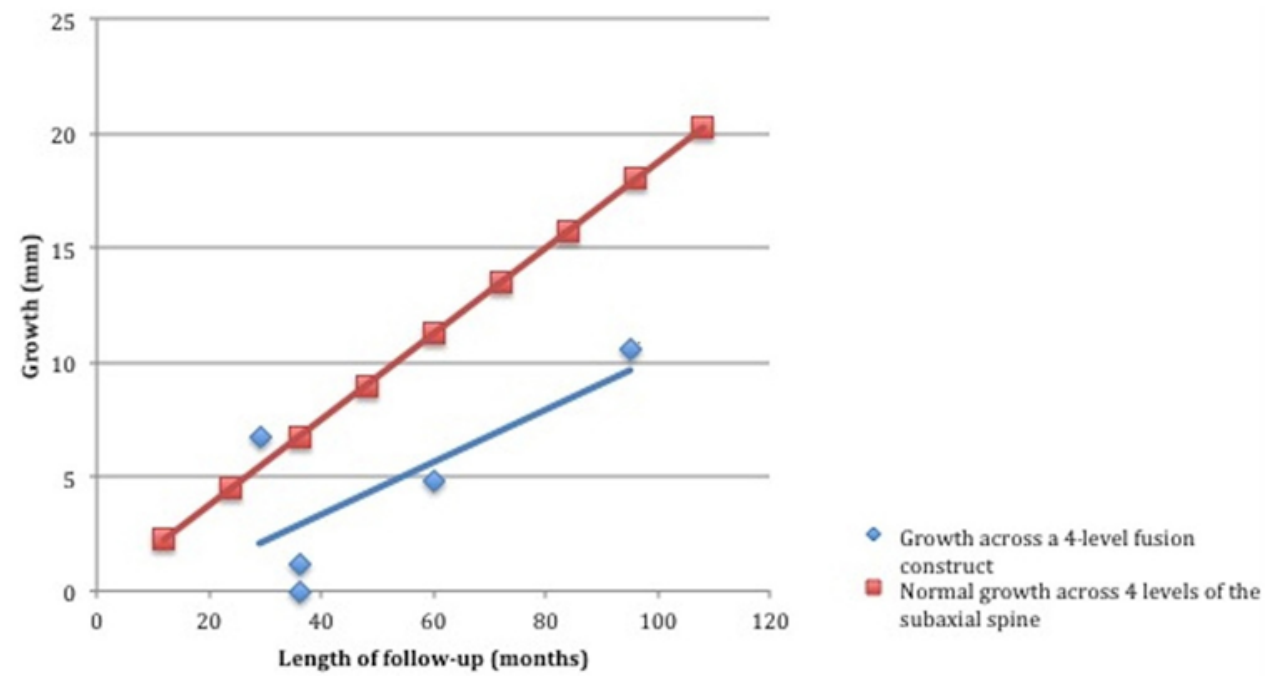

FIG. 6. Growth across the fusion construct in patients with continued growth and at least 2 years of follow-up after a 4-level fusion compared to expected growth across 4 levels of the normal pediatric subaxial spine. The slopes of the lines represent the rate of growth. Figure is available in color online only. 


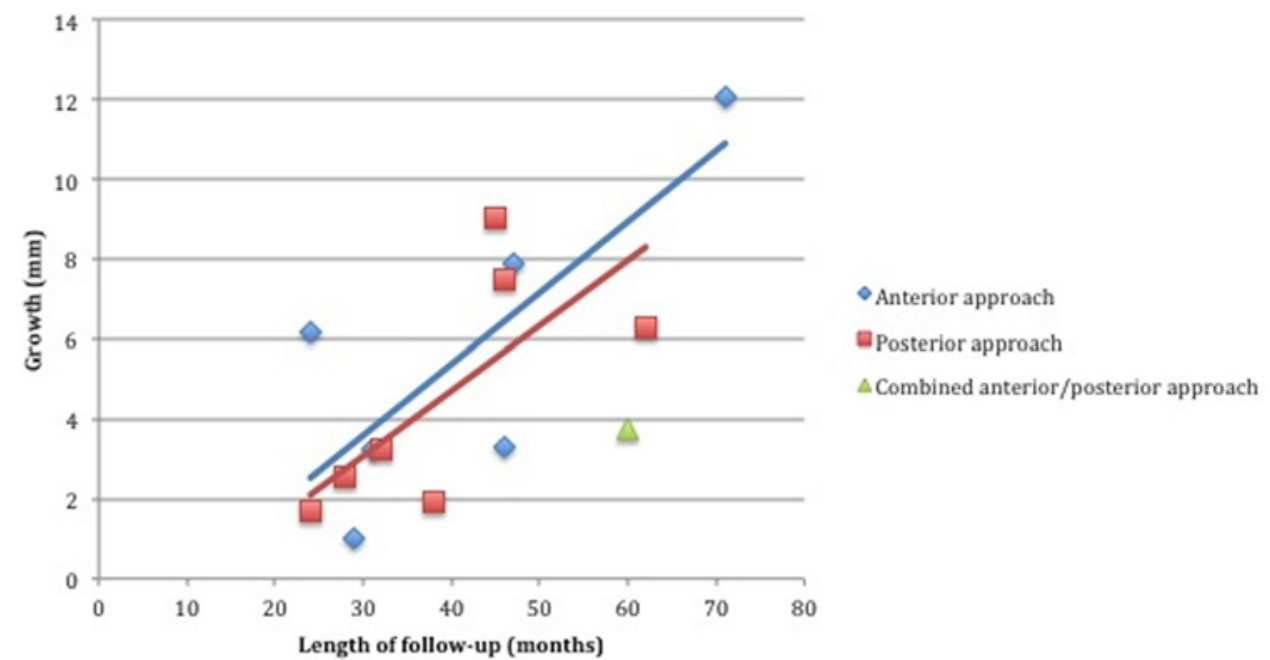

FIG. 7. Growth across the fusion construct in patients with continued growth and at least 2 years of follow-up comparing anterior only, posterior only, and combined anterior/posterior approaches for a 3-level fusion. Figure is available in color online only.

months, demonstrated $7.50 \mathrm{~mm}$ of growth across the fusion construct, which encompassed the entire subaxial cervical spine. This translated to an average of $0.87 \mathrm{~mm}$ per year, which is just less than $30 \%$ of the expected growth in a normal female subaxial cervical spine.

\section{Discussion}

In this multicenter study, we have demonstrated that approximately $60 \%$ of children undergoing rigid internal fixation and fusion of the subaxial spine will demonstrate continued vertical growth across the fusion construct, while nearly $40 \%$ show no growth. The reason for this dichotomy is unclear. However, the patients' age, sex, underlying etiology, number of levels fused, and surgical approach do not seem to account for the difference in growth between the 2 groups. It is possible that normal growth occurs in a pulsatile, rather than continuous, fashion, and so with an average of 33 months of follow-up, we may not be catching the normal growth spurt in the $40 \%$ of patients who appear to have no meaningful growth during that time. Importantly, we have shown that at an average of 33 months follow-up, more than $95 \%$ of children maintain normal cervical alignment without development of unintended fusion or adjacent-level instability.

Prior reports investigating the effects of instrumentation and fusion on the growing cervical spine have been limited because the normal growth patterns in children were unknown. ${ }^{1,2,10,15,17,20,21,29}$ Fortunately, a recent crosssectional CT analysis in normal children from 1 to 18 years of age has been performed. This established normal growth rates of the cervical spine in the pediatric population. This study demonstrated that approximately $75 \%$ of the total growth of the pediatric cervical spine occurs throughout the subaxial spine; this growth is accounted for by both increases in vertebral body height and increases in the height of the disc space. This growth continues up to age 18 in boys and age 14 in girls. Growth in canal diameter, however, is almost fully complete $(92 \%$ in boys and $93.5 \%$ in girls) by 4 years of age..$^{14}$

In our study, $60 \%$ of children had continued vertical growth of their subaxial spine after instrumentation and fusion. While the reason for this is unclear, the proportion is similar to the proportion of children with vertical growth after instrumentation and fusion at the craniovertebral junction (63\% overall). ${ }^{17}$ In the subaxial spine after fusion, the rate of growth compared to the expected rate of growth in normal children decreases with increasing length of fusion construct. Looking at the patients with continued growth, in patients with 2-level constructs, we found growth across the construct to be, on average, $100 \%$ of expected growth; in patients with 3-level constructs, that value decreased to $83 \%$ of expected growth, and in children with 4-level constructs, $79 \%$ of expected growth. Of the 3 patients with constructs that were 5 levels or greater, only one demonstrated any growth across the fusion construct, and at a rate of only $30 \%$ of expected growth.

We hypothesize that the growth seen is due to bone remodeling and normal growth patterns on either end of the fusion construct, with simultaneous inhibition of growth caused by the instrumentation in the intervening vertebral bodies and disc spaces. To evaluate this further, we attempted to evaluate the growth within the construct as compared to the growth of the vertebral bodies at either end of the construct. However, the image quality, the small overall growth measurements, and many cases in which solid bony fusion blurred the boundaries between levels precluded precise measurements within the fusion construct. That being said, our finding is consistent with what has been reported at the craniovertebral junction, and also with the bone remodeling and growth patterns demonstrated around rigid fixation in other parts of the body. $2,8,12,17,19$

Unintended fusion and adjacent-segment instability seem to be very uncommon within the first 4 years following instrumentation and fusion, and the development of malalignment is rare. There was no significant difference in growth or pattern of growth between patients undergoing an anterior-only fusion, those undergoing a posterior-only fusion, and those undergoing a combined anterior/posterior approach (Fig. 7). While crankshaft deformity is an important concept in thoracolumbar fusions, we did not observe this phenomenon in the subaxial cervical spine during the 
follow-up period. Furthermore, 95\% of all patients, regardless of whether they had continued growth postoperatively, had complete clinical resolution or improvement of their symptoms. This suggests that the differences seen in postoperative growth patterns may not have great clinical significance.

There are several limitations of this study. First, this analysis is based on relatively small numbers of patients. We have gathered data from 15 centers to maximize the validity of our findings, but the rarity of subaxial instrumentation and fusion in the pediatric population precludes large numbers of patients. Second, there is no standardization between centers in the modality of follow-up imaging, and due to the radiation exposure, CT scans are not routinely performed postoperatively in these patients. While most follow-up images were lateral plain radiographs, depending on the quality of the imaging study and the different imaging modalities used, the measurements are subject to limitations in technique and measurement error. To minimize this error, all measurements were made by 2 independent neurosurgeons, and any discrepancy of more than $0.5 \mathrm{~mm}$ was double-checked for accuracy and confirmed by a third neurosurgeon. Third, because only static radiographs were analyzed, the biomechanical effects of instrumentation and fusion on the growing pediatric spine cannot be assessed. Fourth, the overall length of follow-up is short (mean 33 months), which is unlikely to detect longterm adjacent-level instability or spinal deformity. Longer follow-up will be needed to determine the incidence of these problems more confidently.

To our knowledge, this is the first multi-institutional study investigating the growth and alignment of the pediatric subaxial cervical spine following rigid instrumentation and fusion. Furthermore, for the first time, normal growth rates of the pediatric cervical spine have been reported that allow comparison. We have demonstrated that approximately $60 \%$ of patients have continued vertical growth of the subaxial spine following surgery, at a rate of $78 \%-100 \%$ of normal, with over $95 \%$ of patients experiencing clinical resolution or significant improvement in their symptoms. In addition, unintended fusion, adjacentsegment instability, and development of malalignment are exceedingly rare. Further studies are needed to determine why vertical growth is not seen in approximately $40 \%$ of patients, as well as the long-term biomechanical effects of surgery on the growing pediatric cervical spine.

\section{References}

1. Ahmed R, Traynelis VC, Menezes AH: Fusions at the craniovertebral junction. Childs Nerv Syst 24:1209-1224, 2008

2. Anderson RC, Kan P, Gluf WM, Brockmeyer DL: Long-term maintenance of cervical alignment after occipitocervical and atlantoaxial screw fixation in young children. J Neurosurg 105 (1 Suppl):55-61, 2006

3. Bailey DK: The normal cervical spine in infants and children. Radiology 59:712-719, 1952

4. Baker DH, Berdon WE: Special trauma problems in children. Radiol Clin North Am 4:289-305, 1966

5. Braakman R, Penning L: The hyperflexion sprain of the cervical spine. Radiol Clin Biol 37:309-320, 1968

6. Brockmeyer D, Apfelbaum R, Tippets R, Walker M, Carey L: Pediatric cervical spine instrumentation using screw fixation. Pediatr Neurosurg 22:147-157, 1995
7. Brockmeyer DL: Advanced surgery for the subaxial cervical spine in children, in Brockmeyer DL (ed): Advanced Pediatric Craniocervical Surgery. New York: Thieme, 2006, pp $109-122$

8. Fearon JA, Munro IR, Bruce DA: Observations on the use of rigid fixation for craniofacial deformities in infants and young children. Plast Reconstr Surg 95:634-638, 1995

9. Fesmire FM, Luten RC: The pediatric cervical spine: developmental anatomy and clinical aspects. J Emerg Med 7:133-142, 1989

10. Garber ST, Brockmeyer DL: Management of subaxial cervical instability in very young or small-for-age children using a static single-screw anterior cervical plate: indications, results, and long-term follow-up. J Neurosurg Spine 24:892-896, 2016

11. Goldberg G, Albert TJ, Vaccaro AR, Hilibrand AS, Anderson DG, Wharton N: Short-term comparison of cervical fusion with static and dynamic plating using computerized motion analysis. Spine (Phila Pa 1976) 32:E371-E375, 2007

12. Goldstein JA, Posnick JC, Wells MD, Slate RK, Thorner PS: An assessment of postnatal growth after in utero long bone osteotomy with fixation. Plast Reconstr Surg 94:160-166, 1994

13. Greaves LL, Van Toen C, Melnyk A, Koenig L, Zhu Q, Tredwell S, et al: Pediatric and adult three-dimensional cervical spine kinematics: effect of age and sex through overall motion. Spine (Phila Pa 1976) 34:1650-1657, 2009

14. Johnson KT, Al-Holou WN, Anderson RC, Wilson TJ, Karnati T, Ibrahim M, et al: Morphometric analysis of the developing pediatric cervical spine. J Neurosurg Pediatr 18:377-389, 2016

15. Kale SS, Ailawadhi P, Yerramneni VK, Chandra PS, Kumar R, Sharma BS, et al: Pediatric bony craniovertebral junction abnormalities: Institutional experience of 10 years. J Pediatr Neurosci 6 (Suppl 1):S91-S95, 2011

16. Kalfas I, Wilberger J, Goldberg A, Prostko ER: Magnetic resonance imaging in acute spinal cord trauma. Neurosurgery 23:295-299, 1988

17. Kennedy BC, D'Amico RS, Youngerman BE, McDowell MM, Hooten KG, Couture D, et al: Long-term growth and alignment after occipitocervical and atlantoaxial fusion with rigid internal fixation in young children. J Neurosurg Pediatr 17:94-102, 2016

18. Kennedy BC, Goldstein HE, Anderson RCE, Brockmeyer DL: Surgery of the pediatric subaxial cervical spine, in Winn HR (ed): Youmans \& Winn Neurological Surgery, ed 7. Philadelphia: Elsevier, 2016

19. Kovács AF, Sauer SN, Stefenelli U, Klein C: Growth of the orbit after frontoorbital advancement using nonrigid suture vs rigid plate fixation technique. J Pediatr Surg 43:2075-2081, 2008

20. Martinez-Del-Campo E, Turner JD, Soriano-Baron H, Newcomb AG, Kalb S, Theodore N: Pediatric occipitocervical fusion: long-term radiographic changes in curvature, growth, and alignment. J Neurosurg Pediatr 18:644-652, 2016

21. Menezes AH: Craniocervical fusions in children. J Neurosurg Pediatr 9:573-585, 2012

22. Pang D, Sun PP: Pediatric vertebral column and spinal cord injuries, in Winn HR (ed): Youmans Neurological Surgery, ed 5. Philadelphia: Saunders, 2004, Vol 3, pp 3515-3557

23. Papin P, Labelle H, Delorme S, Aubin CE, de Guise JA, Dansereau J: Long-term three-dimensional changes of the spine after posterior spinal instrumentation and fusion in adolescent idiopathic scoliosis. Eur Spine J 8:16-21, 1999

24. Townsend EH Jr, Rowe ML: Mobility of the upper cervical spine in health and disease. Pediatrics 10:567-574, 1952

25. Toyama Y, Matsumoto M, Chiba K, Asazuma T, Suzuki N, Fujimura Y, et al: Realignment of postoperative cervical kyphosis in children by vertebral remodeling. Spine (Phila Pa 1976) 19:2565-2570, 1994 
26. Vitale MG, Matsumoto H, Bye MR, Gomez JA, Booker WA, Hyman JE, et al: A retrospective cohort study of pulmonary function, radiographic measures, and quality of life in children with congenital scoliosis: an evaluation of patient outcomes after early spinal fusion. Spine (Phila Pa 1976) 33:1242-1249, 2008

27. White AA III, Johnson RM, Panjabi MM, Southwick WO: Biomechanical analysis of clinical stability in the cervical spine. Clin Orthop Relat Res (109):85-96, 1975

28. White AA III, Panjabi MM: Clinical Biomechanics of the Spine. Philadelphia: Lippincott, 1990

29. Yerramneni VK, Chandra PS, Kale SS, Lythalling RK, Mahapatra AK: A 6-year experience of 100 cases of pediatric bony craniovertebral junction abnormalities: treatment and outcomes. Pediatr Neurosurg 47:45-50, 2011

30. Yuan N, Fraire JA, Margetis MM, Skaggs DL, Tolo VT, Keens TG: The effect of scoliosis surgery on lung function in the immediate postoperative period. Spine (Phila Pa 1976) 30:2182-2185, 2005

\section{Disclosures}

Dr. Limbrick reports receipt of support from Medtronic and
Microbot Medical, Inc., for non-study-related clinical or research effort. Dr. Pahys reports a consultant relationship with DePuy Synthes, Zimmer Biomet, and Globus Medical.

\section{Author Contributions}

Conception and design: Goldstein, Anderson. Acquisition of data: Goldstein, Neira, Aldana, Braga, Brockmeyer, DiLuna, Fulkerson, Hankinson, Jea, Lew, Limbrick, Martin, Pahys, Rodriguez, Rozzelle, Tuite, Wetjen, Anderson. Analysis and interpretation of data: Goldstein, Neira, Anderson. Drafting the article: Goldstein, Banu. Critically revising the article: Goldstein, Hankinson, Limbrick, Rozzelle, Tuite, Anderson. Reviewed submitted version of manuscript: Goldstein, Aldana, Braga, Brockmeyer, DiLuna, Fulkerson, Hankinson, Jea, Lew, Limbrick, Martin, Pahys, Rodriguez, Rozzelle, Tuite, Wetjen, Anderson. Approved the final version of the manuscript on behalf of all authors: Goldstein. Statistical analysis: Goldstein, Banu, Anderson. Administrative/technical/material support: Goldstein, Anderson. Study supervision: Anderson.

\section{Correspondence}

Hannah E. Goldstein: The Neurological Institute, New York, NY. heg2117@columbia.edu. 